\title{
Chronic Exercise Training Protects Aged Cardiac Muscle against Hypoxia
}

Jeanne Y. Wei, Yun-Xia Li, Thomas Lincoln, William Grossman, and David Mendelowitz

Charles A. Dana Research Institute and the Harvard Thorndike Laboratory of Beth Israel Hospital, Department of Medicine, Beth

Israel Hospital and Harvard Medical School; and Geriatric Research Education and Clinical Center, West Roxbury/Brockton Veterans Administration Medical Center, Boston, Massachusetts 02215

\begin{abstract}
To test the hypothesis that chronic exercise may improve tolerance to hypoxia in aged hearts, we compared cardiac function of exercised rats to that of their age-matched, nonexercised controls. Right ventricular papillary muscles were removed from young adult ( 9 mo) and old (24-26 mo) male Fischer 344 rats that were chronically exercised on a rodent treadmill and from their age-matched, nonexercised controls. During isometric contraction, hypoxia depressed contraction and relaxation in all muscles, but to a lesser extent in the exercised groups. A significant exercise effect was observed in the following variables: the maximum developed tension, the maximum rate of tension development, the maximum rate of tension decline, and the time required for the hypoxia to reduce maximum tension by $20 \%$. The maximum rate of tension decline was more sensitive to hypoxia than was the maximum rate of tension development in all groups. Exercise also had an effect on the temperature dependence of cardiac performance during hypoxia. Thus, chronic exercise results in the preservation of both contraction and relaxation during hypoxia for aged as well as young adult hearts.
\end{abstract}

\section{Introduction}

Exercise conditioning of young animals has been reported to result in improved physical work capacity and tolerance to hypoxia, even if there is no change in aerobic energy metabolism (1-3). The lack of change in mitochondrial respiratory capacity or content $(1,2)$ despite an increased work capacity, the increased sarcoplasmic reticular calcium transport, and the increased actomyosin ATPase activity $(3,4)$ may be due to the high intrinsic aerobic reserve in the young (1-5). With advancing age both the heart's physical work capacity and capacity for oxidative energy production are decreased (5-10). These agerelated declines in cardiac performance and aerobic energy metabolism may be reversed by exercise conditioning $(1,6$, 11-13). However, it has not been established whether chronic exercise may improve tolerance to hypoxia in the aged heart. Since relaxation is more sensitive than contraction to hypoxia (14), and since relaxation is enhanced by exercise training in old rats (12), we postulated that chronic exercise will protect the aged cardiac muscle against hypoxia.

Address correspondence to Dr. J. Wei, Beth Israel Hospital, 330 Brookline Avenue, Boston, MA 02215.

Received for publication 10 September 1986 and in revised form 8 August 1988.

J. Clin. Invest.

(c) The American Society for Clinical Investigation, Inc.

0021-9738/89/03/0778/07 \$2.00

Volume 83, March 1989, 778-784
A standard treadmill exercise regimen was imposed on adult male Fischer 344 rats, a mammalian model of aging that is free of atherosclerosis and hypertension (15). Because different results concerning the effect of hypoxia on myocardial relaxation have been reported from studies conducted at different temperatures (16), we chose to perform this study at three temperatures. The left ventricle $(\mathrm{LV})^{1}$ becomes hypertrophied during senescence $(6,8,10-13)$, and exercise conditioning alters cardiac function in hypertrophied hearts whether they are senescent or not $(13,17)$. Therefore, it would be difficult to separate the effect of training on hypertrophied myocardium from its effect on aged myocardium per se when studying LV contractile performance (13). Consequently, to minimize confounding factors we chose to measure mechanical performance of the right ventricular (RV) myocardium, which does not show significant age-related hypertrophy in the rat $(6,8,10,13)$. Finally, young adult rats were also studied to determine the effects not only of chronic exercise but also of age on myocardial tolerance to hypoxia.

\section{Methods}

\section{Animal selection and exercise regimen}

Young adult and old male Fischer 344 rats were obtained from Charles River Breeding Laboratories (Wilmington, MA) or Harlan Sprague Dawley, Inc. (Indianapolis, IN). At the start of the study, the two age groups were aged 4.5 and $21 \mathrm{mo}$, respectively, and 9 and $25 \mathrm{mo}$, respectively, at the end of the study. The males of this colony show a $50 \%$ mortality at $24 \mathrm{mo}$, whether they are exercised or not (see below).

The rats were housed in the Animal Quarters of the Beth Israel Hospital (Boston, MA) at $23 \pm 1^{\circ} \mathrm{C}$ on a 12 -h light/dark cycle and were fed Purina Rat Chow and tap water ad lib. At initiation of the study the rats became acclimated to the personnel and exercise equipment by walking on a slowly moving rodent treadmill for 5-10 min each day for $3 \mathrm{~d}$ (12). Gentle mechanical prodding and verbal conversation at normal intensity were used to encourage continuous running in the rats. Electrical stimulation was not used.

After initiation the rats ran $5 \mathrm{~d} / \mathrm{wk}$ on a motor-driven rodent treadmill for $20 \mathrm{wk}$. The angle of incline was $0^{\circ}$ throughout the exercise training program for both ages. The training protocol was designed to exercise the aged animals at approximately the same percentage of maximal aerobic capacity as the young adult group $(13,18,19)$. Accordingly, the treadmill speeds and exercise durations were selected to exercise the animals of both groups at $\sim 55-65 \%$ maximal aerobic capacity $(1.2 \mathrm{~km} / \mathrm{h}$ for $60 \mathrm{~min}$ in young adult rats, $0.9 \mathrm{~km} / \mathrm{h}$ for $30 \mathrm{~min}$ in aged rats). Two age-matched sedentary control groups of rats were handled similarly and placed on the nonmoving treadmill for the same length of time as the exercise groups.

1. Abbreviations used in this paper: DT, developed tension; dT/dt, rate of tension development; $-\mathrm{dT} / \mathrm{dt}$, rate of tension decline; $\left(\mathrm{dT} / \mathrm{dt}_{\max }\right) /$ DT, maximum rate of tension development normalized for DT; $\left(-\mathrm{dT} / \mathrm{dt}_{\max }\right) / \mathrm{DT}$, maximum rate of tension decline normalized for DT; $L_{\max }$, length at which the developed isometric tension is maximal; $L V$, left ventricle; $R T_{1 / 2}$, time to half relaxation; $R V$, right ventricle. 
At the start the animals were assigned to the control or the exercise group in alternating sequence. Because the males of this rat colony show a $50 \%$ mortality at $24 \mathrm{mo}$, and substantial prior experience from our laboratory has shown that $\sim 10 \%$ of the young adult and $60 \%$ of the old animals usually fail to run satisfactorily, nearly three times as many old rats as young adult rats were initially included in the study cohort. For every old rat assigned to the control group $(n=16)$, two old rats were assigned to the exercise group $(n=32)$. Of the animals assigned to the exercise group, 18 old animals and 1 young animal did not run satisfactorily. They were not placed into the control group but were omitted from the study. Previous studies have shown that the animals that refuse to run do not differ from those that do run with regards to body weight, heart weight, or muscle function (11).

During the course of the exercise protocol, only one young adult rat (a control) died. As expected, mortality was higher among the old animals. 8 of the 16 control and 7 of the 14 exercised rats died before completion of the study. The mortality rates and dates of death were similar between the old exercise and old control groups. The body weight, blood pressure, and activity levels were not different between the animals that died and their age-matched survivors. No acute changes in these parameters were noted before an animal's death, and the distribution of mortality over time was not different between the old exercise and old control groups.

\section{Papillary muscle study}

At the end of the exercise program each young adult (now 9-11 mo) or aged (now 24-26 mo) rat was anesthetized with alpha chloralose/urethane $(500$ and $100 \mathrm{mg} / \mathrm{kg}$, respectively). The heart was removed quickly and immersed in an oxygenated, $\mathrm{pH}$ balanced ( $\mathrm{pH} 7.40$ ) physiological salt solution that contained (in mM) $119.8 \mathrm{NaCl}, 4.5 \mathrm{KCl}$, $25.0 \mathrm{NaHCO}_{3}, 1.2 \mathrm{KH}_{2} \mathrm{PO}_{4}, 1.2 \mathrm{MgSO}_{4}, 0.38 \mathrm{CaCl}_{2}$, and $10.0 \mathrm{dex}-$ trose. A thin RV papillary muscle $\left(<0.5 \mathrm{~mm}^{2}\right.$ in cross-sectional area) was then excised and placed in a temperature-controlled muscle chamber. The remainder of the heart was separated into the LV plus septum and RV, which were gently blotted dry and carefully weighed. These measurements have been demonstrated to agree closely with the calculated wet weights based on a conversion factor (wet/dry $=4.545$ ) derived from the dried weights (13). A tibia was also removed from the animal to serve as an index of body size $(10,13)$.

The excised RV papillary muscle was mounted horizontally in the muscle chamber between two clips, one of which was attached to a strain gauge (Statham UC2; Gould Inc., Houston, TX) for tension measurement. The other clip was attached to a micrometer for precise control of changes in the muscle length. Nonrecirculated bathing fluid, maintained at $28^{\circ} \mathrm{C}$, was passed continuously through the $0.5-\mathrm{ml}$ chamber at $11 \mathrm{ml} / \mathrm{min}$. The muscle was stimulated to contract isometrically at $12 / \mathrm{min}$ using square-wave pulses $(0.2 \mathrm{~ms}$ in duration) that were applied through platinum plate electrodes at a stimulus strength that exceeded threshold by $\sim 25 \%$. After an equilibration period of $\sim 60$ min the muscle was stretched in small increments until it reached the length at which the developed isometric tension was maximal $\left(L_{\max }\right)$. Upon completion of each experiment this muscle length was measured, the muscle was carefully blotted dry and weighed, and its cross-sectional area was calculated $(10,13)$. The muscle was assumed to have a cross-sectional area that was uniform along its length with a density of $1.06 \mathrm{~g} / \mathrm{ml}$. The cross-sectional area was therefore calculated by dividing the mass by the density and the length.

\section{Experimental protocol}

After an additional 30-min equilibration period at $L_{\max }$ in the fluid whose composition was described above, the perfusate solution was changed to one that was also well oxygenated $\left(\mathrm{PO}_{2}=500-600 \mathrm{mmHg}\right)$ but in which $\left[\mathrm{Ca}^{2+}\right]=2.5 \mathrm{mM}$. This concentration of calcium was chosen because under present experimental conditions maximal developed twitch force is achieved at $\left[\mathrm{Ca}^{2+}\right] \mathrm{e}=2.5 \mathrm{mM}$ (10). After yet another 30-min control period, hypoxia was instituted by rapidly replacing the hyperoxic gas mixture of $95 \% \mathrm{O}_{2}-5 \% \mathrm{CO}_{2}$ with a mixture containing $95 \% \mathrm{~N}_{2}-5 \% \mathrm{CO}_{2}$. The muscles remained in the hypoxic environment for $20 \mathrm{~min}$, after which time they were reoxygenated with 95\% $\mathrm{O}_{2}-5 \% \mathrm{CO}_{2}$.

Induction of hypoxia. The gas mixture was bubbled into the warmed perfusate solution through sintered glass. It was also administered directly into the atmosphere surrounding the muscle chamber using tubing tightly fitted into a hole on the side of the muscle chamber canopy. Although the gas mixture of nitrogen/carbon dioxide was anoxic, the muscle chamber canopy (constructed of plexiglass with styrofoam around the edge) was not completely airtight, so that the papillary muscle inside the muscle bath was exposed to relative hypoxia, not anoxia.

Aliquot samples of the muscle chamber perfusate were withdrawn at frequent intervals through a side port in the muscle bath via glass tubing, metal stopcock, and glass syringe. The samples were placed immediately on ice and then analyzed using a $\mathrm{PO}_{2}$ analyzer (Beckman Instruments, Inc., Palo Alto, CA) (Dr. John Eichorn, Beth Israel Hospital Department of Anesthesia). Immediately before applying the hypoxic gas mixture the $\mathrm{PO}_{2}$ in the muscle bath fluid was $544 \pm 18$ mmHg. Less than 5 min after onset of hypoxia the $\mathrm{PO}_{2}$ was $176 \pm 27$ $\mathrm{mmHg}$, and after 10 and $20 \mathrm{~min}$ of hypoxia the muscle bath solution had $\mathrm{PO}_{2}$ levels of $97 \pm 11$ and $73 \pm 13 \mathrm{mmHg}$, respectively. By $10 \mathrm{~min}$ the oxygen tension had nearly reached its asymptotic fluctuating value, since the tension at $20 \mathrm{~min}$ was occasionally observed to fluctuate to a value that was slightly higher than that observed at $10 \mathrm{~min}$. These measurements were obtained consistently at all three temperatures. They were also obtained consistently in the experiments involving both trained and sedentary animals as well as experiments involving young and old animals. The oxygen tensions were similar at the onset of the three temperature periods, so that the muscles started at the same level of oxygen tension for each temperature. The low levels of $\mathrm{PO}_{2}$ that have been reported under comparable (but not identical) conditions by other investigators were 30 and $70 \mathrm{mmHg}(14,16)$. Preliminary studies demonstrated that cardiac depression occurred when the $\mathrm{PO}_{2}$ levels fell below $\sim 300 \mathrm{mmHg}$, a level similar to that reported previously (14).

The isometric force development and its first derivative were obtained from a universal amplifier and a differentiator amplifier (models 13-4615-58 and 13-4615-71; Gould, Inc.). The signals were displayed and recorded on an oscilloscope and strip-chart recorder. They were also recorded using an FM magnetic tape recorder (Hewlett-Packard Co., Palo Alto, CA) for later analysis. Measurements were made during a 30-min control period, after $5^{\prime}, 10^{\prime}, 15^{\prime}$, and $20^{\circ}$ of hypoxia, and during the subsequent 30 -min reoxygenation period. The entire procedure was then repeated (including equilibration) with the temperature of the bathing fluid raised to 32 and then to $38^{\circ} \mathrm{C}$. As noted above, the oxygen tensions were nearly identical at the onset of each procedure and the declines of oxygen tension were also the same.

\section{Data analysis and statistics}

After the resting force and the maximum force developed during an isometric twitch were recorded as described above, the following measurements were made: peak developed tension (DT); time to half relaxation, i.e. time for peak developed tension to decline by $50 \%\left(\mathrm{RT}_{1 / 2}\right)$; maximum rate of tension development normalized for DT [(dT/ $\left.\left.\mathrm{dt}_{\max }\right) / \mathrm{DT}\right]$; and maximum rate of tension decline normalized for DT [(-dT/dt $\left.\left.t_{\max }\right) / D T\right]$.

The values are expressed as means \pm SEM. Differences in mean baseline values between the two age groups were assessed by the unpaired $t$ test. The Bonferroni correction was applied for multiple comparisons to reduce the possibility of chance significance. For each age group the effect of exercise and $\mathrm{PO}_{2}$ level on cardiac muscle performance during hypoxia were determined through application of analysis of variance (three-factor with replication). If the sample variances were demonstrated to be equivalent by Levene's statistic, Dunnett's test was applied to determine which of the times were associated with values that were different from the initial values (20). Analysis of covariance was used to compare the slopes and intercepts of the lines of decline in performance during hypoxia (20). 


\section{Results}

At the end of the chronic exercise program the young adult exercised group remained virtually unchanged in weight, while their age-matched controls progressively gained weight (Table I). In contrast, the old exercised rats not only did not gain but actually lost weight slightly, while their age-matched controls gained weight. The basal systolic blood pressure was similar among the four groups (young exercised $=134 \pm 4$, young control $=130 \pm 5$, old exercised $=139 \pm 6$, old control $=133 \pm 6$ $\mathrm{mmHg}$ ). The basal heart rate was also comparable among the groups (young exercised $=409 \pm 14$, young control $=394 \pm 9$, old exercised $=384 \pm 11$, old control $=379 \pm 12 / \mathrm{min}$ ). The young adult exercised group demonstrated a significant decrease in resting heart rate compared with their age-matched controls (young exercised $=-64 \pm 25$, young control $=-21 \pm 7$, $P<0.05$ ). The old exercised group showed a significant decline in resting systolic pressure (old exercised $=-20 \pm 6$, old control $=-4 \pm 7, P<0.05$ ). Both age groups demonstrated improved exercise tolerance, requiring less prodding and showing less fatigue, at the end of the training period. These changes show that both age groups adapted to exercise conditioning. In the sedentary animals significant LV hypertrophy, but no significant RV hypertrophy, was present in the aged compared with the young adult control rats. Chronic exercise did not alter the heart weight/tibia length ratio in either age group (Table I).

The effects of chronic exercise on the isometric contractile response to hypoxia are presented in Table II. Hypoxia resulted in significant declines in the contractile performance of both the young adult and senescent groups. At baseline there were no significant differences between aged exercised and aged control rats or between young adult exercised and young adult control rats in the contractile parameters, DT and (dT/ $\mathrm{dt}_{\max }$ /DT. However, during hypoxia significant differences between the exercised and age-matched controls became apparent for both the young adult and senescent animals (Table II). Chronic exercise clearly increased myocardial tolerance and preserved contractile performance during hypoxia. The DT and $\left(-\mathrm{dT} / \mathrm{dt}_{\max }\right) / \mathrm{DT}$ in response to hypoxia were both significantly preserved in the exercised animals, as compared with the controls for both age groups. The time required for a $20 \%$ depression of developed tension (from baseline value) was significantly lengthened (by $>60 \%$ ) as a result of chronic exercise in both age groups (Fig. 1). The time course of the de-
Table II. Effect of Hypoxia on Mechanical Performance of $R V$ Papillar Muscles in Young Adult and Old Exercised Rats and Their Age-matched Controls at $32^{\circ} \mathrm{C}$

\begin{tabular}{|c|c|c|c|c|c|}
\hline \multirow[b]{2}{*}{ Variable } & \multirow[b]{2}{*}{ Basal values } & \multicolumn{4}{|c|}{$\begin{array}{l}\text { Performance (percent of basal value } \\
\text { during hypoxia) }\end{array}$} \\
\hline & & $5 \mathrm{~min}$ & $10 \mathrm{~min}$ & $15 \min$ & $20 \mathrm{~min}$ \\
\hline \multicolumn{6}{|l|}{ Young adult } \\
\hline \multicolumn{6}{|l|}{$\mathrm{DT}\left(\mathrm{mN} / \mathrm{mm}^{2}\right)$} \\
\hline Control (8) & $13.2 \pm 2.4$ & $90 \pm 1$ & $80 \pm 3$ & $71 \pm 3$ & $64 \pm 3$ \\
\hline Exercised (9) & $16.6 \pm 1.8$ & $97 \pm 1^{*}$ & $89 \pm 2^{\ddagger}$ & $82 \pm 3^{8}$ & $76 \pm 4^{\S}$ \\
\hline \multicolumn{6}{|c|}{$\left(\mathrm{dT} / \mathrm{dt}_{\max }\right) / \mathrm{DT}\left(s^{-1}\right)$} \\
\hline Control (8) & $18.8 \pm 0.9$ & $93 \pm 1$ & $83 \pm 3$ & $76 \pm 4$ & $70 \pm 4$ \\
\hline Exercised (9) & $18.1 \pm 0.3$ & $96 \pm 1^{8}$ & $90 \pm 2^{\S}$ & $84 \pm 3$ & $79 \pm 4$ \\
\hline \multicolumn{6}{|c|}{$\left(-\mathrm{dT} / \mathrm{dt}_{\max }\right) / \mathrm{DT}\left(s^{-1}\right)$} \\
\hline Control (8) & $13.3 \pm 0.8$ & $90 \pm 2$ & $79 \pm 3$ & $71 \pm 4$ & $64 \pm 4$ \\
\hline Exercised (9) & $\cdot 12.1 \pm 0.4$ & $97 \pm 2^{\ddagger}$ & $89 \pm 3^{8}$ & $82 \pm 3^{\S}$ & $76 \pm 4^{\S}$ \\
\hline \multicolumn{6}{|l|}{ Old adult } \\
\hline \multicolumn{6}{|l|}{$\mathrm{DT}\left(\mathrm{mN} / \mathrm{mm}^{2}\right)$} \\
\hline Control (8) & $21.4 \pm 4.7$ & $89 \pm 2$ & $82 \pm 2$ & $72 \pm 2$ & $62 \pm 3$ \\
\hline Exercised (7) & $20.0 \pm 6.1$ & $96 \pm 2$ & $89 \pm 2^{8}$ & $83 \pm 2^{\S}$ & $78 \pm 2^{\ddagger}$ \\
\hline \multicolumn{6}{|c|}{$\left(\mathrm{dT} / \mathrm{dt}_{\max }\right) / \mathrm{DT}\left(s^{-1}\right)$} \\
\hline Control (8) & $17.2 \pm 0.8$ & $90 \pm 2$ & $84 \pm 3$ & $75 \pm 2$ & $65 \pm 4$ \\
\hline Exercised (7) & $16.8 \pm 0.6$ & $97 \pm 1$ & $92 \pm 2^{\S}$ & $87 \pm 2^{\S}$ & $83 \pm 2^{\ddagger}$ \\
\hline \multicolumn{6}{|c|}{$\left(-\mathrm{dT} / \mathrm{dt}_{\max }\right) / \mathrm{DT}\left(s^{-1}\right)$} \\
\hline Control (8) & $9.6 \pm 0.8$ & $91 \pm 2$ & $81 \pm 2$ & $72 \pm 2$ & $62 \pm 3$ \\
\hline Exercised (7) & $12.4 \pm 0.7$ & $96 \pm 2$ & $91 \pm 2^{\ddagger}$ & $84 \pm 2^{\S}$ & $78 \pm 2^{\ddagger}$ \\
\hline
\end{tabular}

$\left[\mathrm{Ca}^{2+}\right]_{\mathrm{e}}=2.5 \mathrm{mM}$.

${ }^{*} P<0.001,{ }^{\ddagger} P<0.01,{ }^{8} P<0.05$, compared with age-matched controls.

cline and restoration of DT in response to hypoxia is shown in Fig. 2. When expressed as percent of basal value the declines of young and old control DT were almost identical and the declines of young and old exercised DT were almost identical. In old but not in young rats the hypoxia-induced reduction in the rate of tension development $(\mathrm{dT} / \mathrm{dt})$ was significantly less in exercised rats than in controls (Fig. 3). Chronic exercise was associated with significantly less hypoxia-induced reduction in $-\mathrm{dT} / \mathrm{dt}$ in both age groups (Fig. 3). The indices of relaxation appeared to be more sensitive to hypoxia than those of contraction, demonstrating larger percent declines at 10,15, and 20 min of hypoxia (Fig. 3).

Table I. Effect of Age and Exercise on Body and Heart Weights

\begin{tabular}{|c|c|c|c|c|}
\hline \multirow[b]{2}{*}{ Variable } & \multicolumn{2}{|c|}{ Young adult rats $(9.5 \mathrm{mo})$} & \multicolumn{2}{|c|}{ Senescent rats ( $25 \mathrm{mo})$} \\
\hline & Control (8) & Exercised (9) & Control (8) & Exercised (7) \\
\hline Body weight, initial $(g)$ & $272 \pm 6$ & $262 \pm 3$ & $380 \pm 20$ & $358 \pm 18$ \\
\hline Body weight, terminal $(g)$ & $350 \pm 7^{*}$ & $265 \pm 11^{\ddagger}$ & $403 \pm 12$ & $321 \pm 23^{\S}$ \\
\hline$\Delta$ Body weight $(g)$ & $78 \pm 9$ & $3 \pm 11^{\ddagger}$ & $23 \pm 13$ & $-37 \pm 28$ \\
\hline LV weight/body weight $\left(\times 10^{-3}\right)$ & $1.85 \pm 0.04$ & $2.30 \pm 0.11^{\prime \prime}$ & $2.05 \pm 0.10$ & $2.51 \pm 0.15^{\S}$ \\
\hline RV weight/body weight $\left(\times 10^{-3}\right)$ & $0.45 \pm 0.02$ & $0.54 \pm 0.04$ & $0.41 \pm 0.04$ & $0.48 \pm 0.04$ \\
\hline $\mathrm{LV}$ weight/tibia length $(\mathrm{g} / \mathrm{cm})$ & $0.158 \pm 0.006$ & $0.150 \pm 0.005$ & $0.184 \pm 0.009$ & $0.179 \pm 0.011$ \\
\hline $\mathrm{RV}$ weight $/$ tibia length $(\mathrm{g} / \mathrm{cm})$ & $0.037 \pm 0.003$ & $0.036 \pm 0.004$ & $0.037 \pm 0.005$ & $0.035 \pm 0.002$ \\
\hline Papillary muscle cross-sectional area $\left(\mathrm{mm}^{2}\right)$ & $0.40 \pm 0.04$ & $0.38 \pm 0.05$ & $0.40 \pm 0.07$ & $0.42 \pm 0.04$ \\
\hline
\end{tabular}

${ }^{*} P<0.001$, compared with initial value. ${ }^{\ddagger} P<0.001 ;{ }^{\S} P<0.05 ; " ~ P<<0.005$, compared with age-matched controls. 


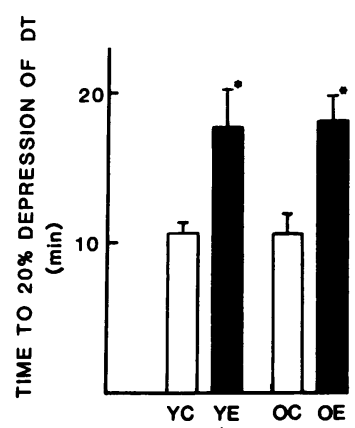

Figure 1. Duration of hypoxia required for a $20 \%$ reduction in cardiac performance (DT) of isometric twitch in $R V$ papillary muscles of young adult control $(Y C)$, young adult exercised $(Y E)$, old adult control $(O C)$, and old adult exercised $(O E)$ rats at $32^{\circ} \mathrm{C} * P<0.05$ vs. age-matched control animals.

The interaction of chronic exercise and temperature on cardiac response to hypoxia was also investigated (Table III). At baseline both the contractile and the relaxation processes were quickened as temperature was increased for all groups. Relaxation was more temperature sensitive than contraction, and the percent change in basal values of $\left(-\mathrm{dT} / \mathrm{dt}_{\max }\right) / \mathrm{DT}$ between 28 and $38^{\circ} \mathrm{C}$ was greater in the old control (309\%) than in the young adult control group $(263 \%, P<0.01)$. The protective effect of exercise training on cardiac function during hypoxia was present at 32 and $37^{\circ} \mathrm{C}$, being more pronounced at $32^{\circ} \mathrm{C}$. At $28^{\circ} \mathrm{C}$ exercise conferred no noticeable protective effect for $\left(\mathrm{dT} / \mathrm{dt}_{\max }\right) / \mathrm{DT}$ in young adults and for $\mathrm{RT}_{1 / 2}$ for both age groups. DT, $d T / d t$, and $-\mathrm{dT} / \mathrm{dt}$ fell more with hypoxia at 38 than at 28 or $32^{\circ} \mathrm{C}$ for both groups of young adult rats (Table III). The hypoxia-induced reduction in these parameters was smaller in young adult exercised than in young adult control rats.

Interestingly, hypoxia had opposite effects on the $\mathrm{RT}_{1 / 2}$ at 28 and $38^{\circ} \mathrm{C}$ (Table III and Fig. 4). At $28^{\circ} \mathrm{C}$ hypoxia shortened

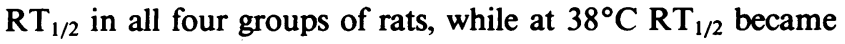
prolonged with hypoxia in all four groups. At $32^{\circ} \mathrm{C}$ the young adult exercised and control groups also demonstrated lengthening of $\mathrm{RT}_{1 / 2}$ during hypoxia. However, the direction of change was different for the old exercised and old control groups: $\mathrm{RT}_{1 / 2}$ became prolonged in the old exercised and shortened in the old controls. Apparently the transitional temperature from shortening to lengthening of $\mathrm{RT}_{1 / 2}$ during hyp-

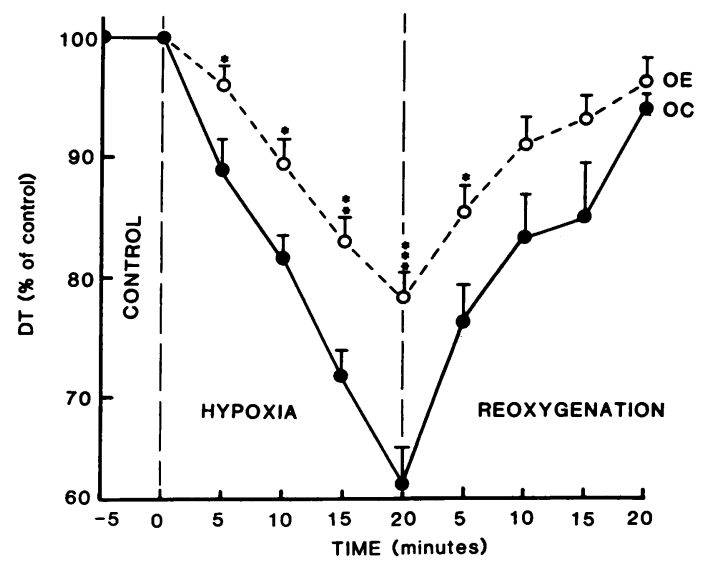

Figure 2. Effect of hypoxia and reoxygenation on DT in isometrically contracting $\mathrm{RV}$ papillary muscles from aged exercised and respective age-matched sedentary control rats at $32^{\circ} \mathrm{C},\left[\mathrm{Ca}^{2+}\right]=2.5$ mM. ${ }^{*} P<0.05 ;{ }^{* *} P<0.01 ;{ }^{* * *} P<0.001$ vs. age-matched controls. Abbreviations are same as in Fig. 1.
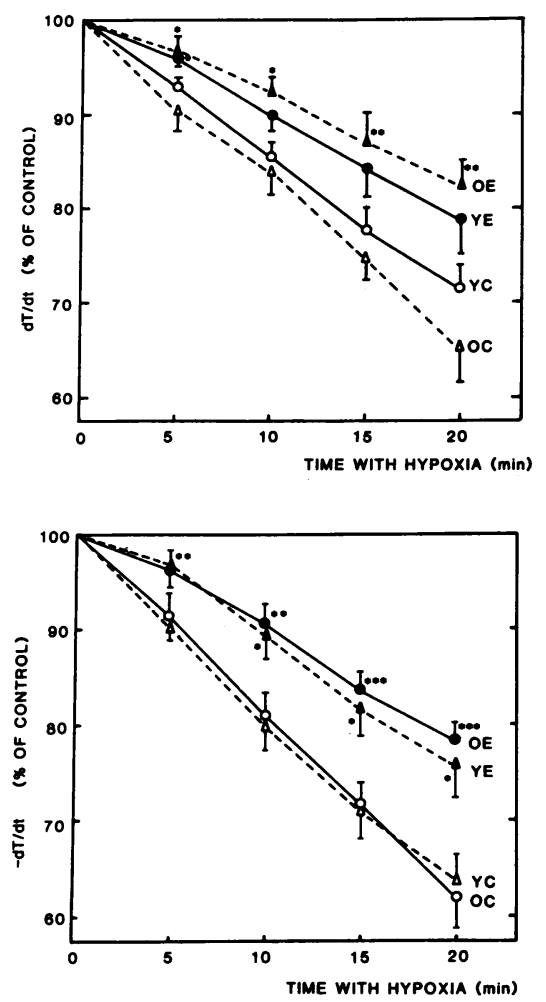

Figure 3. The effect of hypoxia on $\mathrm{dT} / \mathrm{dt}(t o p)$ and $-\mathrm{dT} / \mathrm{dt}$ (bottom) of isometrically contracting $R V$ papillary muscles from young adult and old adult exercised and respective agematched sedentary control rats at $32^{\circ} \mathrm{C},\left[\mathrm{Ca}^{2+}\right]$ $=2.5 \mathrm{mM} .{ }^{*} P<0.05$; ** $P<0.01$ vs. agematched control animals. Abbreviations are same as Fig. 1.

oxia occurs at a slightly lower temperature in the younger animals. In the senescent animal exercise training is associated with a lowering of this transitional temperature to a level similar to young adults.

\section{Discussion}

The present study has three major findings. First, chronic exercise training enhanced myocardial tolerance to hypoxia with regard to both force development and relaxation, and this enhanced tolerance was exhibited by both young and old animals. The protective effect of exercise was most pronounced at $32^{\circ} \mathrm{C}$ and barely noticeable at $28^{\circ} \mathrm{C}$. Hypoxia impaired the relaxation phase of the isometric twitch more than the contractile phase in both age groups. Second, the transitional temperature at which hypoxia neither shortened nor prolonged myocardial relaxation is higher in the aged rat than in the young adult rat. Third, exercise training reversed this age effect and lowered the transitional temperature of the aged exercised myocardium toward that of the young adult.

The exercised old rats in this study demonstrated a clear training effect in spite of the lack of a significant heart rate change. This is because ( $a$ ) they lost weight compared with the age-matched sedentary controls, which actually gained weight, even though both groups were maintained on an ad lib diet; $(b)$ they demonstrated a decrease in resting blood pressure relative to the blood pressure of age-matched controls; $(c)$ they were trained on the same exercise regimen that had been shown previously to produce a clear training effect on cardiac muscle function (13); and $(d)$ the performance of cardiac muscle of the old exercise group again shows a clear change with training (Table II).

The younger exercised adult rats demonstrated a decline in resting heart rate and the older exercised rats showed a decline 
Table III. Effect of Temperature and Exercise Training on Cardiac Response to Hypoxia in Young Adult and Old Exercised Rats and Their Age-matched Controls at $\left[\mathrm{Ca}^{2+}\right]_{e}=2.5 \mathrm{mM}$

\begin{tabular}{|c|c|c|c|c|c|c|}
\hline \multirow[b]{2}{*}{ Variable } & \multicolumn{2}{|c|}{$28^{\circ} \mathrm{C}$} & \multicolumn{2}{|c|}{$32^{\circ} \mathrm{C}$} & \multicolumn{2}{|c|}{$38^{\circ} \mathrm{C}$} \\
\hline & Basal value & Hypoxia (20) & Basal value & Hypoxia (20) & Basal value & Hypoxia (20) \\
\hline & & \% basal & & \% basal & & \% basal \\
\hline \multicolumn{7}{|c|}{$\left(\mathrm{dT} / \mathrm{dt}_{\max }\right) / \mathrm{DT}\left(s^{-1}\right)$} \\
\hline Control (8) & $13.1 \pm 0.76$ & $85 \pm 2$ & $19 \pm 1$ & $70 \pm 3$ & $25 \pm 2$ & $55 \pm 4$ \\
\hline Exercised (9) & $12.8 \pm 0.27$ & $86 \pm 3$ & $18 \pm 0.3$ & $79 \pm 4$ & $27 \pm 1$ & $66 \pm 5$ \\
\hline \multicolumn{7}{|c|}{$\left(-\mathrm{dT} / \mathrm{dt}_{\max }\right) / \mathrm{DT}\left(s^{-1}\right)$} \\
\hline Control (8) & $7.6 \pm 0.53$ & $74 \pm 3$ & $13 \pm 1$ & $64 \pm 4$ & $20 \pm 2$ & $47 \pm 3$ \\
\hline Exercised (9) & $6.9 \pm 0.39$ & $80 \pm 3$ & $12 \pm 0.4$ & $76 \pm 4^{*}$ & $22 \pm 0.3$ & $59 \pm 5$ \\
\hline \multicolumn{7}{|l|}{$\mathrm{RT}_{1 / 2}(m s)$} \\
\hline Control (8) & $85.6 \pm 3.36$ & $96 \pm 1$ & $50 \pm 2$ & $102 \pm 3$ & $27 \pm 2$ & $105 \pm 5$ \\
\hline Exercised (9) & $95.1 \pm 5.01$ & $95 \pm 2$ & $54 \pm 2$ & $101 \pm 2^{\ddagger}$ & $25 \pm 0.2$ & $104 \pm 4^{\ddagger}$ \\
\hline \multicolumn{7}{|l|}{ Old adult } \\
\hline Control (7) & $12.4 \pm 0.8$ & $83 \pm 3$ & $17 \pm 1$ & $65 \pm 4$ & $24 \pm 1$ & $60 \pm 4$ \\
\hline Exercised (7) & $13.1 \pm 0.3$ & $88 \pm 4$ & $18 \pm 1$ & $83 \pm 2^{\S}$ & $29 \pm 1$ & $73 \pm 3^{\S}$ \\
\hline \multicolumn{7}{|c|}{$\left(-\mathrm{dT} / \mathrm{dt}_{\max }\right) / \mathrm{DT}\left(s^{-1}\right)$} \\
\hline Control (7) & $5.5 \pm 0.52$ & $80 \pm 4$ & $10 \pm 1$ & $62 \pm 3$ & $17 \pm 1$ & $58 \pm 4$ \\
\hline Exercised (7) & $7.1 \pm 0.77$ & $84 \pm 2$ & $12 \pm 1$ & $78 \pm 2^{\S}$ & $23 \pm 1$ & $72 \pm 3^{8}$ \\
\hline \multicolumn{7}{|l|}{$\mathrm{RT}_{1 / 2}(m s)$} \\
\hline Control (7) & $131.9 \pm 7.82^{\prime \prime}$ & $95 \pm 3$ & $82 \pm 3^{\prime \prime}$ & $95 \pm 3$ & $36 \pm 2^{\prime}$ & $111 \pm 6^{\ddagger}$ \\
\hline Exercised (7) & $100.2 \pm 11.73^{\prime}$ & $94 \pm 4$ & $54 \pm 3$ & $107 \pm 2^{\ddagger \S}$ & $26 \pm 0.4^{8}$ & $114 \pm 4^{\ddagger}$ \\
\hline
\end{tabular}

All values are means \pm SEM. ${ }^{*} P<0.05 ;{ }^{\S} P<0.005$, compared with age-matched controls. ${ }^{\ddagger} P<0.05$, compared with value at $28^{\circ} \mathrm{C}$.

' $P<0.05$; $P<0.005$, compared with young adult controls.

in resting blood pressure. We believe that these differences indicate an age-related cardiovascular adaption to exercise training, i.e., bradycardia in young adults and hypotension in the aged rats (10). Other observers have also noted the absence of a significant heart rate change during exercise training (10, 21-23) and some investigators have noted a lowering of blood pressure alone (24). Thus, it is likely that the magnitude of heart rate change is a function of the species, the mode of

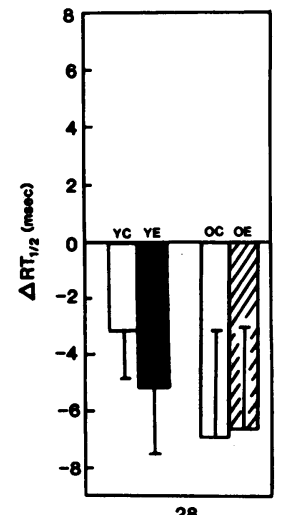

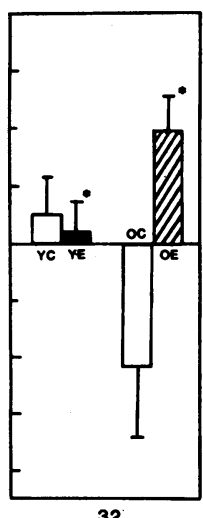

32

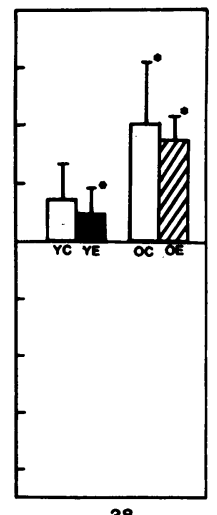

Temperature $\left({ }^{\circ} \mathrm{C}\right)$

Figure 4. Effect of hypoxia ( $20 \mathrm{~min}$ ) on cardiac relaxation (changes in time to $R T_{1 / 2}$ ) in isometrically contracting $R V$ papillary muscles from young adult and aged exercised rats and their respective agematched controls at 28,32 , and $38^{\circ} \mathrm{C}$. ${ }^{*} P<0.05$, compared with value at $28^{\circ} \mathrm{C}$. Abbreviations are same as in Fig. 1. exercise training, and the age of subjects, as well as the intensity and duration of exercise conditioning (10).

Our finding that moderate treadmill exercise conditioning did not result in significant RV hypertrophy is in agreement with other observers who have found that such hypertrophy consistently accompanies only swimming exercise (25-29). Our results demonstrate that substantial functional changes in contraction and relaxation of cardiac muscle may accompany exercise conditioning of moderate intensity even in the absence of significant myocardial hypertrophy $(6,11,12,25-29)$.

The mechanism(s) underlying the exercise-induced protection of contractile response (rate of force development) to hypoxia is not established, but several possibilities may be considered. First, exercise-induced increases in cardiac actomyosin (30) or myosin ATPase (31) activity may enable the cardiac muscle of trained animals to maintain a higher level of performance during hypoxia than their sedentary age-matched controls. A second possibility is that the efficiency of utilization of high energy compounds may be higher in the trained heart (30-32). However, exercise training has not been shown to alter myocardial ATP, creatine phosphate, or lactic acid levels at baseline or during hypoxia (32). Studies have also failed to show a training effect on mitochondrial number, mitochondrial oxygen uptake (oxidation of pyruvate), respiratory control index, phosphorylation/oxidation ratio, or ATPase activity (32). Nevertheless, exercise training may enhance cellular metabolic down-regulatory capacity by decreasing or maintaining glycolytic flux at the same level during hypoxia (reversed Pasteur effect), or it may decrease permeability of membranes or lower the sodium/potassium ATPase activity 
(33). These latter mechanisms have been demonstrated to be present in hypoxia-tolerant cells and absent in hypoxia-sensitive cells (34).

Furthermore, it has been demonstrated that cardiac mitochondrial oxidative phosphorylation in response to stress declines with age and that in the rat this decline becomes apparent between 10 and 15 mo of age (35). Studies performed on aged rats using both isolated and perfused heart preparations have shown improved cardiac oxidative performance with training $(5,6,11,12)$. This improved performance of the senescent trained myocardium is accompanied by increased LV cytochrome $c$ concentrations and rates of oxidation of glutamate-malate, palmitoylcarnitine, and succinate (5), none of which occurs in the exercise-trained young adult hearts $(5,32)$. Therefore, training-induced enhancement of myocardial physical performance is associated with increased oxidative energy metabolism in the aged heart.

The effect of training on hypoxia-induced changes in myocardial relaxation probably involves the sarcoplasmic reticulum. It has been demonstrated that an increase in the rate of $\mathrm{Ca}^{2+}$ accumulation occurs in the sarcoplasmic reticulum of young adult hearts after chronic exercise (7-8 wk of swimming), and this is associated with faster relaxation times (36). Our study supports other reports that hypoxia has a relatively greater inhibitory effect on relaxation than on contraction $(14,16)$.

Furthermore, we found that the relaxation phase also appeared to be more temperature sensitive than the contraction phase. Our observations are similar to those reported for rat skeletal muscle (37) and for rat LV papillary muscle (38), whose calcium sequestration is correspondingly temperature sensitive (37). Our finding that exercise training in the old rat improved cardiac muscle performance during both hypoxia and hypothermia is compatible with the notion that these training-induced improvements may share the same mecha$\operatorname{nism}(\mathbf{s})$.

In summary, the present study demonstrates that even in the absence of cardiac hypertrophy exercise training reverses and enhances the cardiac performance of senescent and young adult rats during hypoxia and hypothermia. The relaxation phase appears to be more sensitive than the contraction phase to changes in temperature, especially in the aged rat.

\section{Acknowledgments}

We thank Dr. J. Eichorn for technical assistance, Dr. D. Rigney for helpful suggestions, and J. Longstreet, S. Dahlgren, and J. Ragland for assistance in manuscript preparation.

This study was supported in part by HL-29295, National Heart, Lung and Blood Institute, and the Veterans Administration.

\section{References}

1. Oscai, L. B., P. A. Mole, and J. O. Holloszy. 1971. Effects of exercise on cardiac weight and mitochondria in male and female rats. Am. J. Physiol. 220:1944-1948.

2. Rockstein, M., J. Chesky, and T. Lopez. 1978. Calcium sensitivity of myocardial actomyosin ATPase in young and mature male Fischer rats: a brief note. Mech. Ageing Dev. 8:413-416.

3. Scheuer, J., and C. M. Tipton. 1977. Cardiovascular adaptations to physical training. Annu. Rev. Physiol. 39:221-251.

4. Penparkgul, S., A. Malhotra, T. Schaible, and J. Scheuer. 1980.
Cardiac contractile proteins and sarcoplasmic reticulum in hearts of rats trained by running. J. Appl. Physiol. 48:409-413.

5. Starnes, J. W., R. E. Beyer, and D. W. Edington. 1983. Myocardial adaptations to endurance exercise in aged rats. Am. J. Physiol. 245:H560-H566.

6. Wei, J. Y., and B. J. Gersh. 1987. Heart disease in the elderly. Curr. Probl. Cardiol. 12:1-65.

7. Abu-Erreish, G. M., J. R. Neely, J. T. Whitmer, V. Whitman, and D. R. Sanadi. 1977. Fatty acid oxidation by isolated perfused working hearts of aged rats. Am. J. Physiol. 232 (Endocrinol. Metab. Gastrointest. Physiol. 1):E258-E262.

8. Chen, J. C., J. B. Warshaw, and D. R. Sanadi. 1972. Regulation of mitochondrial respiration in senescence. J. Cell. Physiol. 80:141148.

9. Hansford, R. G. 1978. Lipid oxidation by heart mitochondria from young adult and senescent rats. Biochem. J. 170:285-295.

10. Wei, J. Y., H. A. Spurgeon, and E. G. Lakatta. 1984. Excitation-contraction in rat myocardium: alterations with adult aging. Am. J. Physiol. 246:H784-H791.

11. Wei, J. Y., J. Ragland, and Y. X. Li. 1987. Effect of exercise training on resting blood pressure and heart rate in adult and aged rats. J. Gerontol. 42:11-16.

12. Spurgeon, H. A., M. F. Steinbach, and E. G. Lakatta. 1983. Chronic exercise prevents characteristic age-related changes in rat cardiac contraction. Am. J. Physiol. 244:H513-H518.

13. Li, Y.-X., T. Lincoln, D. Mendelowitz, W. Grossman, and J. Y. Wei. 1986. Age-related differences in effect of exercise training on cardiac muscle function in rat. Am. J. Physiol. 251:H12-H18.

14. St. John Sutton, M. G., E. L. Ritman, and N. F. Paradise. 1980. Biphasic changes in maximum relaxation rate during progressive hypoxia in isometric kitten papillary muscle and isovolumic rabbit ventricle. Circ. Res. 47:516-524.

15. Wei, J. Y., D. Mendelowitz, N. Anastasi, and J. W. Rowe. 1986. Maintenance of carotid baroreflex function in advanced age in the rat. Am. J. Physiol. 250:R1047-R1051.

16. Frist, W. H., I. Palacios, and W. J. Powell, Jr. 1978. Effect of hypoxia on myocardial relaxation in isometric cat papillary muscle. $J$. Clin. Invest. 61:1218-1224.

17. Schaible, T. F., G. J. Ciambrone, J. M. Capasso, and J. Scheuer. 1984. Cardiac conditioning ameliorates cardiac dysfunction associated with renal hypertension in rats. J. Clin. Invest. 73:1086-1094.

18. Bedford, T. G., C. M. Tipton, N. C. Wilson, R. A. Oppliger, and C. V. Gisolf. 1979. Maximum oxygen consumption of rats and its changes with various experimental procedures. J. Appl. Physiol. 47:1278-1283.

19. Shepherd, R. E., and P. D. Gollinck. 1976. Oxygen consumption of rats at different exercise intensities. Pfluegers Arch. Eur. J. Physiol. 362:219-222.

20. Snedecor, G. W., and W. G. Cochran. 1980. Statistical Methods. 7th ed. Iowa State College Press, Ames, IA. 215-233.

21. Lin, Y.-C., and S. M. Horvath. 1972. Autonomic nervous control of cardiac frequency in the exercise-trained rat. J. Appl. Physiol. 33:796-799.

22. Gleeson, T. T., W. J. Mullin, and K. M. Baldwin. 1983. Cardiovascular responses to treadmill exercise in rats: effects of training. $J$. Appl. Physiol. Respir. Environ. Exercise Physiol. 54:789-793.

23. Mackintosh, I. C., I. C. Dormehl, A. L. van Gelder, and M. du Pleissis. 1983. Blood volume, heart rate, and left ventricular ejection fraction changes in dogs before and after exercise during endurance training. Am. J. Vet. Res. 44:1960-1962.

24. Shepherd, R. E., M. L. Kuehne, K. A. Kenno, J. L. Durstine, T. W. Balon, and J. P. Rapp. 1982. Attenuation of blood pressure increases in Dahl salt-sensitive rats by exercise. J. Appl. Physiol. Respir. Environ. Exercise Physiol. 52:1608-1613.

25. Cutilletta, A. F., K. Edmiston, and R. T. Dowell. 1979. Effect of a mild exercise program on myocardial function and the development of hypertrophy. J. Appl. Physiol. 42 (Respir. Environ. Exercise Physiol. 2):354-380. 
26. Dowell, R. T., C. M. Tipton, and R. J. Tomanek. 1976. Cardiac enlargement mechanisms with exercise training and pressure overload. J. Mol. Cell Cardiol. 8:407-418.

27. Hickson, R. C., G. T. Hammons, and J. O. Holosozy. 1979. Development and regression of exercise-induced cardiac hypertrophy in rats. Am. J. Physiol. 236(2):H268-H272.

28. Schaible, T. F., and J. Scheuer. 1979. Effects of physical training by running or swimming on ventricular performance of rat hearts. J. Appl. Physiol. Respir. Environ. Exercise Physiol. 46(4):854-860.

29. Singh, S., F. C. White, and C. M. Bloor. 1982. Effect of acute exercise stress in cardiac hypertrophy. II. Quantitative ultrastructural changes in the myocardial cell. Virchows Arch. B Cell Pathol. 39(3):293-303.

30. Bhan, A. K., and J. Scheuer. 1972. Effects of physical training on cardiac actomyosin adenosine triphosphatase activity. Am. J. Physiol. 223:1486-1490.

31. Bhan, A. K., and J. Scheuer. 1974. Effects of physical training on cardiac myosin ATPase activity. Am. J. Physiol. 228:1178-1182.

32. Carey, R. A., C. M. Tipton, and D. R. Lund. 1976. Influence of training on myocardial responses of rats subjected to conditions of ischemia and hypoxia. Cardiovasc. Res. 10:359-367.

33. Hochachka, P. W. 1986. Defense strategies against hypoxia and hypothermia. Science (Wash. DC). 231:231-233.

34. Hochachka, P. W. 1985. Proc. Int. Union Compar. Physiol. Biochem., Vol. 1.

35. Starnes, J. W., R. E. Beyer, and D. W. Edington. 1981. Effects of age and cardiac work in vitro on mitochondrial oxidative phosphorylation and $\left({ }^{3} \mathrm{H}\right)$-leucine incorporation. J. Gerontol. 2:130-135.

36. Penpargkul, S., A. Malhotra, T. Schaible, and J. Scheuer. 1980. Cardiac contractile proteins and sarcoplasmic reticulum in hearts of rats training by running. J. Appl. Physiol. Respir. Environ. Exercise Physiol. 48:409-413.

37. Stein, R. B., T. Gordon, and J. Shriver. 1982. Temperature dependence of mammalian muscle contractions and ATPase activities. Biophys. J. 40:97-107.

38. Bottinelli, R., C. Poggesi, L. Ricciardi, and R. Minelli. 1982. The influence of temperature on the relaxation properties of rat papillary muscle. Boll. Soc. Ital. Biol. Sper. 58:177-183. 